Article

\title{
On the Fracture Behavior of a Creep Resistant 10\% Cr Steel with High Boron and Low Nitrogen Contents at Low Temperatures
}

\author{
Roman Mishnev, Nadezhda Dudova, Rustam Kaibyshev and Andrey Belyakov *(D) \\ Laboratory of Mechanical Properties of Nanostructured Materials and Superalloys, Belgorod State University, \\ Belgorod 308015, Russia; mishnev@bsu.edu.ru (R.M.); dudova@bsu.edu.ru (N.D.); \\ rustam_kaibyshev@bsu.edu.ru (R.K.) \\ * Correspondence: belyakov@bsu.edu.ru; Tel.: +7-4722-565457
}

Received: 16 November 2019; Accepted: 17 December 2019; Published: 18 December 2019

check for updates

\begin{abstract}
An advanced, high chromium, creep-resistant steel was subjected to the tensile tests and three-point bending tests of Charpy V-notch specimens at temperatures of -196 to $20^{\circ} \mathrm{C}$. The steel exhibited ductile fracture under tension tests at all of the temperatures studied. The mechanical properties, i.e., strength and uniform elongation, were enhanced with a decrease in temperature down to $-140{ }^{\circ} \mathrm{C}$. Transgranular, dimpled fracture remained the primary fracture mechanism under tension. On the other hand, the results obtained with Charpy V-notch specimens suggested the ductile-brittle transition (DBT). Full embrittlement was observed at temperatures of $-60{ }^{\circ} \mathrm{C}$ and $-150^{\circ} \mathrm{C}$ upon impact tests and three-point bending tests, respectively, when the unstable crack started to propagate without remarkable plastic deformation. The DBT temperature of $-27^{\circ} \mathrm{C}$ for the present steel corresponded to the $28 \mathrm{~J}$ impact transition temperature, $\mathrm{T}_{28 \mathrm{~J}}$, when the maximum impact stress matched the maximal true tensile stress.
\end{abstract}

Keywords: martensitic steel; tensile test; bending test; fracture; brittle-ductile transition

\section{Introduction}

High-chromium steels belonging to ferrite-martensite types are advanced materials for crucial applications in fossil power plants because of their outstanding mechanical properties at elevated temperatures [1,2]. Such steels are commonly subjected to austenitization at temperatures above approx. $1050^{\circ} \mathrm{C}$, followed by air quenching and tempering at temperatures of $750{ }^{\circ} \mathrm{C}$ to $770{ }^{\circ} \mathrm{C}$ for 2 to $4 \mathrm{~h}$. The processed microstructures are characterized by a high dislocation density in martensite laths/blocks/packets and numerous second phase particles [1-6]. Among the latter ones are relatively coarse carbides of $\mathrm{M}_{23} \mathrm{C}_{6}$-type that precipitated mainly along the lath/block/packed boundaries, and nanoscale MX-type carbides/nitrides that homogeneously distributed throughout the tempered martensite [1-5]. This microstructure provides high toughness at ambient temperatures and a low ductile-brittle transition temperature (DBTT) of about $-60{ }^{\circ} \mathrm{C}[3,5,7-10]$. Moreover, these steels are characterized by a rather high impact toughness of approx. $20 \mathrm{~J}$ below DBTT even at $-140{ }^{\circ} \mathrm{C}$, and quite low was the $28 \mathrm{~J}$ impact transition temperature $\left(T_{28 \mathrm{~J}}\right)$ of around $-100^{\circ} \mathrm{C}$ [7-11]. An aging at service temperature may decrease the impact toughness down to four times along with an increase in DBTT up to $100{ }^{\circ} \mathrm{C}[1,12-14]$. Nevertheless, an impact toughness above $40 \mathrm{~J} / \mathrm{cm}^{2}$ remained at ambient temperature, ensuring the reliability of steam turbine parts made of high-chromium steels [1]. Anyway, the temperature of DBT should be accurately predicted for being in order to provide the safe exploitation of the steel products.

Nowadays, a type of high-chromium martensitic steels with a high content of boron and a low content of nitrogen is considered as an advanced material for high temperature application because 
of its improved creep properties [4,15-19]. This specific alloying design results in a precipitation of $\mathrm{M}_{23} \mathrm{C}_{6}$ carbides along with boron-bearing $\mathrm{M}_{23}(\mathrm{BC})_{6}$ particles [17-20]. On the other hand, such steels are characterized by a relatively high temperature of DBT because of numerous $\mathrm{M}_{23} \mathrm{C}_{6}$ precipitates that form dense arrays along the lath/block/packet boundaries and promote both the void nucleation/growth and the formation of critical cracks susceptible to rapid expansion [21]. As a result, DBTT as determined by impact tests of Charpy V-notch specimens for the $10 \% \mathrm{Cr}$ steels, is about $+10^{\circ} \mathrm{C}$, that is $73 \mathrm{~K}$ higher than that for P92-type steels [21].

There is an ambiguity in the use of DBTT estimated from the impact tests as a halfway point between the upper and lower shelf-absorbed energies to ensure the structural integrity of the engineering components fabricated from high-chromium steels [11]. Chatterjee et al. suggested to use the $28 \mathrm{~J} \mathrm{impact}$ transition temperature as the characteristic one for the structural components [11]. High-chromium steels like P91- and P92-type steels are sufficiently tough even at temperatures below DBTT $[7,8,10]$. Brittle fracture was not observed on flat specimens of these steels under tension condition down to cryogenic temperatures [7]. Thus, the fracture behaviors of these steels with and without notch are quite different. Studying the fracture behavior of advanced heat-resistant steels in detail is essential to prevent the sudden failure of power plant components made of these steels at ambient temperatures during construction and/or repair.

The present work is intended to expand our previous study, which has been focused on the impact toughness of a $10 \% \mathrm{Cr}$ steel with high boron and low nitrogen contents, to comprehensive analysis of the fracture toughness under static and dynamic loading conditions. Therefore, the primary aim of this study is to clarify the fracture behavior of an advanced $10 \% \mathrm{Cr}$ steel, considering the stress concentrator effect and comparing the standard tensile tests of flat specimens with the bending tests of Charpy V-notch specimens. The second aim is to evaluate DBTT for static and dynamic [21] loading tests of Charpy V-notch specimens.

\section{Experimental}

The studied material was a high-chromium steel alloyed with $0.1 \% \mathrm{C}, 10.0 \% \mathrm{Cr}, 0.7 \% \mathrm{Mo}$, $0.05 \% \mathrm{Nb}, 0.2 \% \mathrm{~V}, 0.003 \% \mathrm{~N}, 0.008 \% \mathrm{~B}, 2.0 \% \mathrm{~W}$ and $3.0 \% \mathrm{Co}$ (in wt $\%$ ). Austenitization was carried out at $1060{ }^{\circ} \mathrm{C}$ for $30 \mathrm{~min}$. Then, the steels samples were air cooled followed by tempering at $770{ }^{\circ} \mathrm{C}$ for $3 \mathrm{~h}$. The flat specimens with a gauge length of $35 \mathrm{~mm}$ and a cross-section of $7 \mathrm{~mm} \times 3 \mathrm{~mm}$ were cut from the tempered samples and then subjected to tensile tests under isothermal conditions at different temperatures varying from $-140{ }^{\circ} \mathrm{C}$ to $20^{\circ} \mathrm{C}$ and at an initial strain rate of $2 \times 10^{-3} \mathrm{~s}^{-1}$. The fracture behavior was examined by the three-point bending tests at temperatures from $-196^{\circ} \mathrm{C}$ to $80^{\circ} \mathrm{C}$ with a crosshead speed of $2 \mathrm{~mm} / \mathrm{min}$ corresponding to an initial strain rate of $2 \times 10^{-3} \mathrm{~s}^{-1}$ using ordinary V-notch Charpy specimens. Both the tensile tests and the bending tests were carried out using an Instron 5882 (Illinois Tool Works Inc., Norwood, MA, USA) testing machine with an Instron SFL 3119-408 environmental chamber. The same holding time of $30 \mathrm{~min}$ at the measurement temperature was used for all samples to avoid any possible artefacts caused by variations of cooling duration [22]. The present results were compared with those obtained under dynamic loading by impact tests of standard V-notch Charpy specimens that were reported in a previous work [21].

The structural characterizations were carried out using a Jeol JEM-2100 (JEOL Ltd., Tokyo, Japan) transmission electron microscope (TEM) equipped with an INCA energy dispersive $X$-ray spectrometer (EDX); and the fractography studies were performed with a Quanta 200 (FEI, Hillsboro, OR, USA) scanning electron microscope (SEM). The specimens for structural observations were electro-polished using $10 \%$ perchloric acid solution in a glacial acetic acid. The transverse lath/subgrain sizes were measured on the representative TEM images by the linear intercept method counting all the clear visible boundaries and subboundaries. The dislocation densities inside the laths and/or subgrains were measured by counting the individual dislocations that observed on typical TEM images of dislocation substructures observed under multiple beam contrast conditions. The dispersed particles were studied by TEM, combining the EDX and selected area diffraction methods. 


\section{Results}

\subsection{Microstructure}

The tempered microstructure of the present steel consists of the prior austenite grains with an average size of $35 \mu \mathrm{m}$ and the tempered laths with an average width of $0.4 \mu \mathrm{m}$ (Figure 1). A rather high dislocation density of $1.7 \times 10^{14} \mathrm{~m}^{-2}$ is observed inside the tempered laths. The particles of $\mathrm{M}_{23} \mathrm{C}_{6}$-type precipitate during tempering [4,18]. These particles with the mean size of $100 \mathrm{~nm}$ mainly locate on various high-angle boundaries, while those with a smaller size of about 60 nm precipitate on low-angle lath boundaries. Uniformly distributed MX-type carbonitrides are characterized by an increased content of niobium. The mean size of these particles is $30 \mathrm{~nm}$.

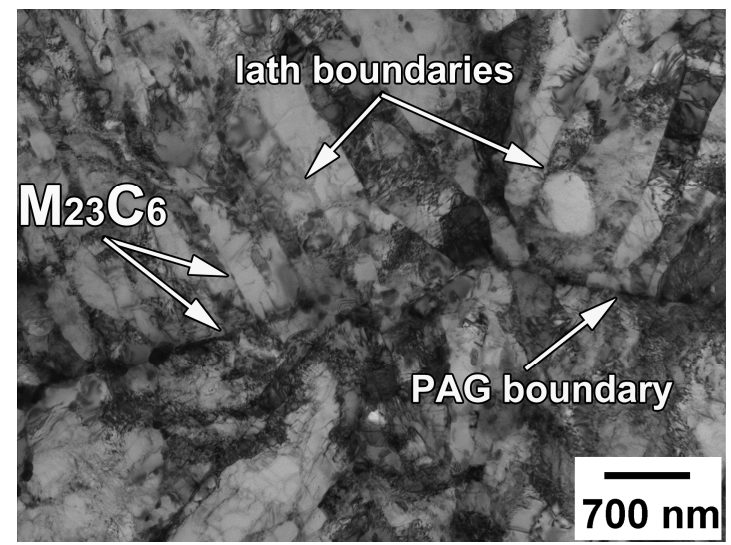

Figure 1. Transmission electron microscopy (TEM) micrograph of the tempered microstructure in a $10 \%$ Cr steel.

\subsection{Tensile Properties}

Typical engineering stress-elongation curves and corresponding true stress-strain curves that are obtained at different temperatures are shown in Figure 2. The values of yield strength $\left(\sigma_{0.2}\right)$, ultimate tensile strength (UTS), uniform elongation $\left(\mathrm{El}_{\mathrm{u}}\right)$ and total elongation $\left(\mathrm{El}_{\mathrm{t}}\right)$ are summarized in Table 1 . Continuous yielding $[7,23,24]$ is observed at all temperatures. The true stress-strain curves exhibit a noticeable strain hardening that provides the large uniform elongation. The maximal true stress $\left(\sigma_{\max }\right)$ is achieved at a strain ranging from 0.06 to 0.14 . It should be noted that the shape of the flow curves is almost the same irrespective of the deformation temperature. A decrease in temperature from 20 to $-140{ }^{\circ} \mathrm{C}$ increases the ability of the steel to resist the plastic instability and fracture. As a result, an increase in UTS from $700 \mathrm{MPa}$ to $925 \mathrm{MPa}$ and an increase in total elongation from $16 \%$ to $23.5 \%$ are observed. Thus, the $10 \% \mathrm{Cr}$ steel strengthens and becomes more ductile at cryogenic temperatures.

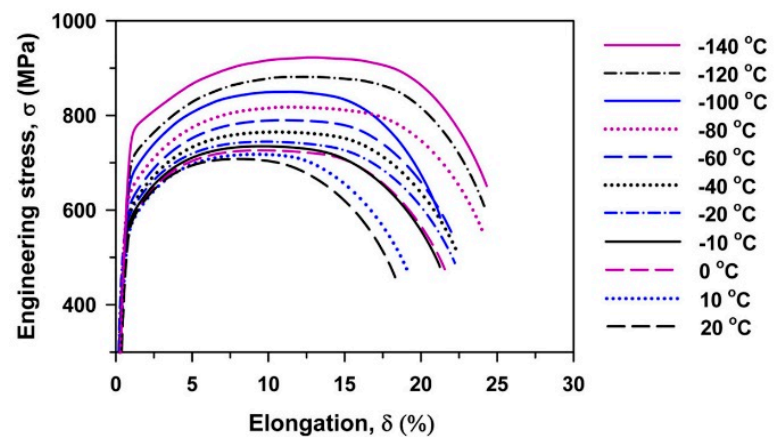

(a)

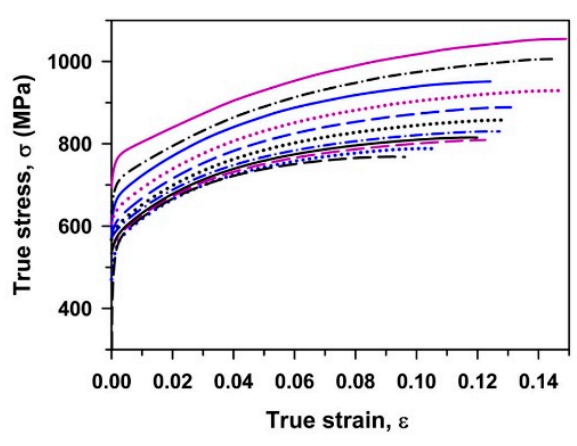

(b)

Figure 2. Engineering stress-elongation curves (a) and true stress-strain curves (b). 
Table 1. Yield strength $\left(\sigma_{0.2}\right)$, ultimate tensile strength (UTS), maximal true stress $\left(\sigma_{\mathrm{m}}^{\mathrm{T}}\right)$, uniform elongation $\left(\mathrm{El}_{\mathrm{u}}\right)$, and total elongation $\left(\mathrm{El}_{\mathrm{t}}\right)$ of a $10 \% \mathrm{Cr}$ steel at different temperatures.

\begin{tabular}{cccccccccccc}
\hline \multirow{2}{*}{ Parameters } & \multicolumn{10}{c}{ Temperature, $^{\circ} \mathbf{C}$} \\
\cline { 2 - 13 } & $\mathbf{2 0}$ & $\mathbf{1 0}$ & $\mathbf{0}$ & $\mathbf{- 1 0}$ & $\mathbf{- 2 0}$ & $\mathbf{- 4 0}$ & $\mathbf{- 6 0}$ & $\mathbf{- 8 0}$ & $\mathbf{- 1 0 0}$ & $\mathbf{- 1 2 0}$ & $\mathbf{- 1 4 0}$ \\
\hline$\sigma_{0.2}, \mathrm{MPa}$ & 550 & 560 & 570 & 575 & 590 & 600 & 615 & 640 & 665 & 705 & 765 \\
$\mathrm{UTS}, \mathrm{MPa}$ & 710 & 720 & 725 & 735 & 745 & 765 & 790 & 820 & 850 & 880 & 925 \\
$\sigma_{\mathrm{m}}{ }^{\mathrm{T}}, \mathrm{MPa}$ & 780 & 790 & 810 & 815 & 830 & 860 & 890 & 930 & 950 & 1005 & 1055 \\
$\mathrm{El}_{\mathrm{u}}, \%$ & 7.2 & 8.9 & 9.1 & 7.7 & 9.7 & 8.8 & 10 & 10.8 & 10.5 & 10 & 12.1 \\
$\mathrm{El}_{\mathrm{t}}, \%$ & 17.7 & 18.5 & 21 & 20.6 & 21.6 & 21.8 & 21.5 & 23.4 & 20.5 & 23.4 & 23.5 \\
\hline
\end{tabular}

\subsection{Fracture Toughness}

The impact toughness of the $10 \%$ Cr steel was studied in a previous paper [21] and can be briefly summarized here as follows. DBT corresponding to a half between the upper and lower shelf energies was observed at $10^{\circ} \mathrm{C}$. The upper shelf region with an energy of $335 \mathrm{~J} / \mathrm{cm}^{2}$ is located at $T \geq 80^{\circ} \mathrm{C}$, and the lower shelf region is situated at $T<-40^{\circ} \mathrm{C}$. The fracture appearance transition temperature (FATT) corresponding to the $50 \%$ of ductile surface fracture matches DBTT. The $28 \mathrm{~J}$ transition temperature, $T_{28 \mathrm{~J}}$, is about $-27^{\circ} \mathrm{C}$. Typical impact load-deflection curves obtained at various temperatures are represented in Figure 3. The maximum loads, $P_{m}$, the general yield loads, $P_{G Y}$, the well-defined specific loads, $P_{F}$, corresponding to the unstable crack propagation, and the loads for the fracture arrest, $P_{A},[12,25]$ are marked in Figure 3.

Figure 4 shows typical load-deflection curves obtained during the three-point bending tests. It is seen that the fracture occurs in a viscous manner at temperatures of $T \geq 40^{\circ} \mathrm{C}$. The maximum load is attained after a relatively large deflection of around $4 \mathrm{~mm}$, which is a half of the transverse size of the central specimen section. Sharp $P_{\mathrm{F}}$ corresponding to the onset of unstable cleavage can be recognized at temperatures of $T \leq 20^{\circ} \mathrm{C}$. An arrest load and total deflection decrease with temperature.

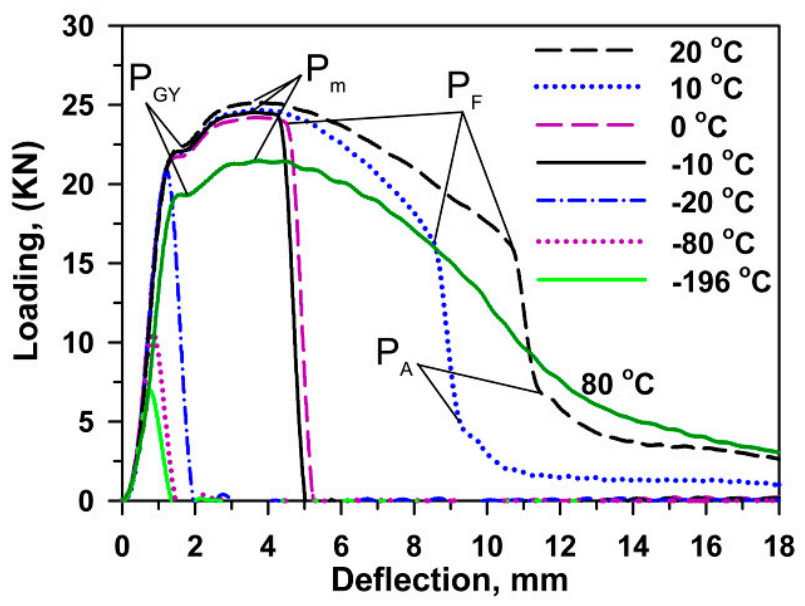

Figure 3. Load-deflection curves during dynamic loading. $P_{\mathrm{GY}}$ is the load at general yield, $P_{\mathrm{m}}$ is the maximum load, $P_{\mathrm{F}}$ is the cleavage fracture load and $P_{\mathrm{A}}$ is the arrest load. Reprinted from [21] with permission from Elsevier. 


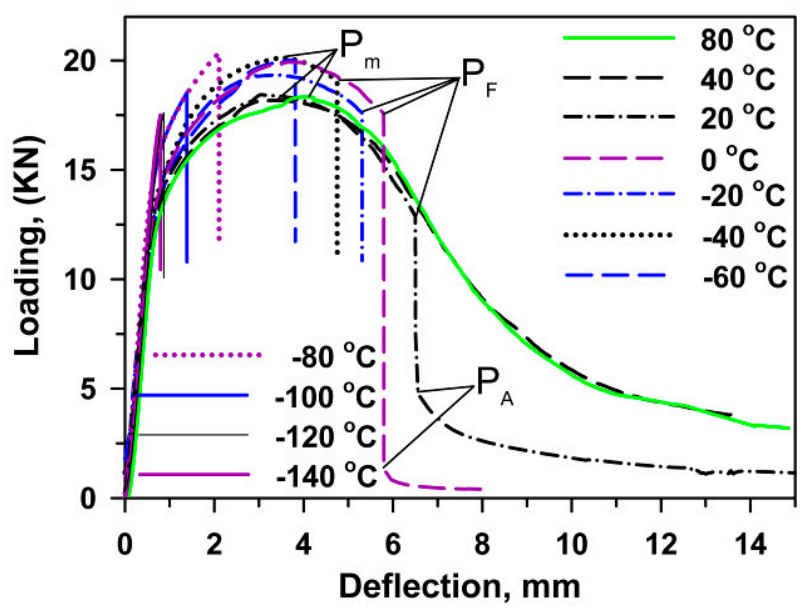

Figure 4. Load-deflection curves obtained during the three-point bending tests at different temperatures.

$P_{\mathrm{m}}$ is the maximum load, $P_{\mathrm{F}}$ is the cleavage fracture load, $P_{\mathrm{A}}$ is the arrest load.

The fracture toughness curve obtained from the three-point bending tests and the fraction of shear fracture are shown in Figure 5. The upper shelf region of Charpy V-notch energy is observed at $T \geq 50^{\circ} \mathrm{C}$. The transition region is observed in the temperature interval of -120 to $20^{\circ} \mathrm{C}$. At $T<-120^{\circ} \mathrm{C}$, the steel is fully brittle with a low absorbed energy of $9 \mathrm{~J} / \mathrm{cm}^{2}$, which remains unchanged down to liquid nitrogen temperature. At $T=-50{ }^{\circ} \mathrm{C}$ corresponding to a halfway point between the upper and lower shelf energies in Figure 5, which can be considered as DBTT for the three-point bending tests, the Charpy V-notch energy is about $100 \mathrm{~J} / \mathrm{cm}^{2}$. The values of FATT and $T_{28 \mathrm{~J}}$ are $-22^{\circ} \mathrm{C}$ and $-90^{\circ} \mathrm{C}$, respectively. Therefore, almost full brittle fracture occurs during the three-point bending tests at $T<-90^{\circ} \mathrm{C}$.

The transition from the upper to lower shelf region in Figure 5 is accompanied with a gradual increase in $P_{\mathrm{m}}$ (Figure 4). At $T>\mathrm{DBTT}$, unstable crack propagation follows a stage of stable crack propagation. The onset of unstable crack propagation appears at $T<$ DBTT just after the maximum load is reached. At the lower shelf region, the load at which the unstable crack propagation appears decreases with decreasing temperature and a very small deflection is observed. Hence, the high fracture toughness during the three-point bending tests is attributed to a high displacement of the pendulum required for attaining the maximum load followed by stable crack propagation. The suppression of stable crack propagation corresponds to DBTT. The premature of unstable cleavage at the hardening stage occurs in the temperatures below DBTT.

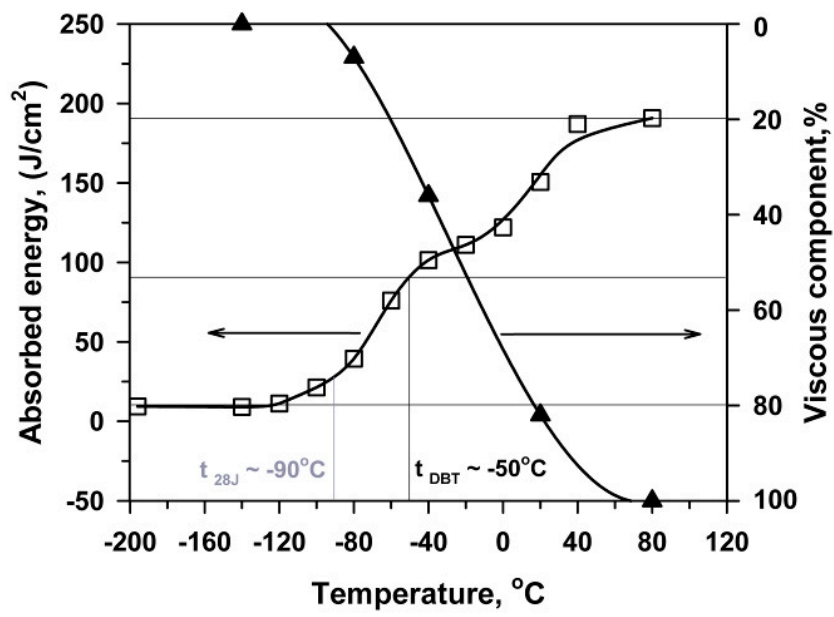

Figure 5. Effect of temperature on the V-notch Charpy absorbed energy during the three-point bending tests and the shear fracture percentage. 


\subsection{Fractography}

\subsubsection{Tension Tests}

Figure 6 represents the overall views of the fracture surfaces of tensioned specimens. The transgranular mode is the main fracture mechanism at all temperatures. Three well-known fracture signatures, i.e., fibrous zone, radial zone and shear-lip zone [26,27], can be distinguished in Figure 6. The dimension of these zones depends upon temperature. It is known [26,27] that the triaxial stresses in the necked section develop the highest shear stress at the center of a tensile specimen forming a central crack. Next, this crack grows slowly, forming the fibrous zone of ductile fracture with an elliptical shape [26,27]. At ambient temperature, a large fibrous zone consists of fine and deep dimples (Figure $6 a, b$ ), indicating the ductile character of subcritical crack growth that requires high energy. The transition to shallow dimples and increasing dimple dimensions occurs with decreasing temperature. The size of the fibrous zone tends to decrease with a decrease in temperature. An evidence for the intergranular fracture can be found at cryogenic temperatures. The canyons with slip features on walls are observed along the boundaries of prior austenite grains at $-140{ }^{\circ} \mathrm{C}$. However, the role of this fracture mechanism is minor.
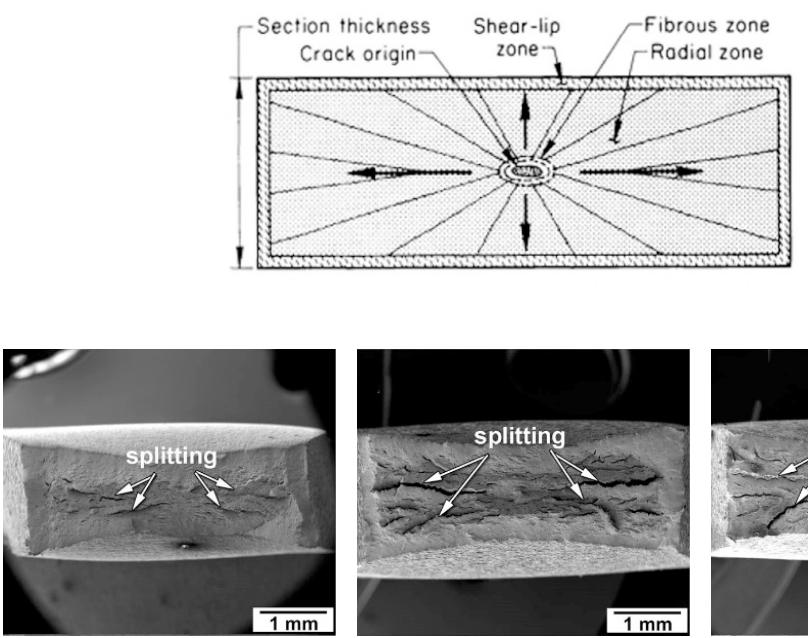

(a)

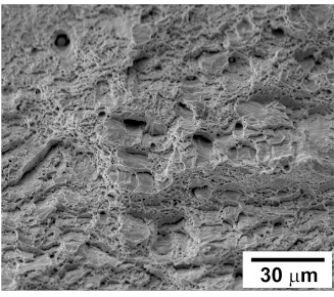

(b)

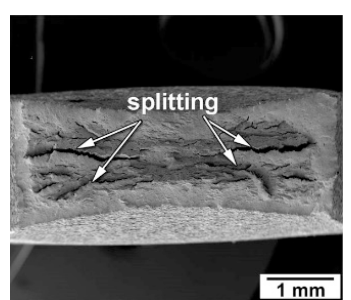

(c)

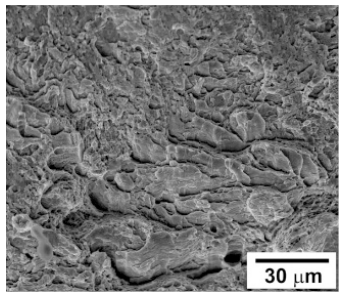

(d)

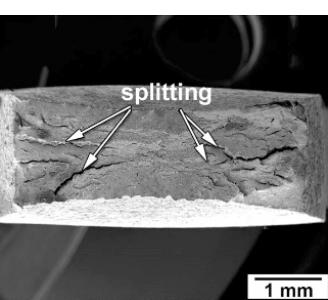

(e)

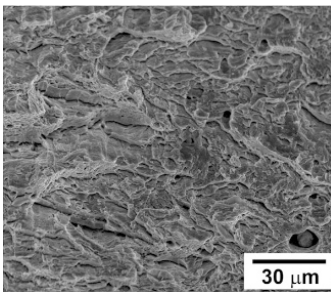

(f)

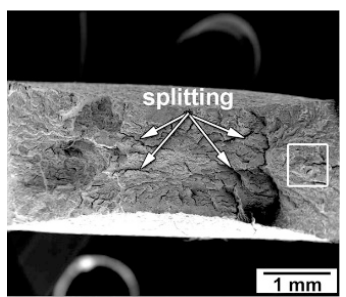

(g)

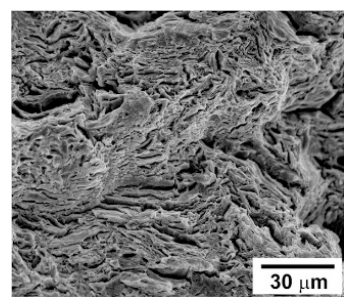

(h)

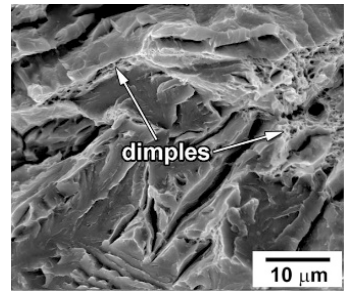

(i)

Figure 6. Scanning electron microscopy (SEM) micrographs showing the fracture surfaces of the specimens tensioned at $20{ }^{\circ} \mathrm{C}(\mathbf{a}, \mathbf{b}),-40{ }^{\circ} \mathrm{C}(\mathbf{c}, \mathbf{d}),-60{ }^{\circ} \mathrm{C}(\mathbf{e}, \mathbf{f})$, and $-140{ }^{\circ} \mathrm{C}(\mathbf{g}, \mathbf{h}, \mathbf{i})$ along with a scheme of the fracture surface markings showing specific areas of rectangular tensile specimen.

The relief of the radial zone with the coarse radial marks, secondary cracking and crack branching is indicative of increasing the crack growth rate. The dimple fracture and the coarse curved radial marks in the radial zones support this conclusion. A decrease in the temperature leads to an expansion of the radial zone, increases the number of secondary cracks and promotes crack branching. The shear-lip zone of quasi-cleavage fracture can be distinguished at $T \geq-40{ }^{\circ} \mathrm{C}$.

This zone is apparently one of unstable crack propagation. The size of the shear-lip zone decreases as temperature decreases. At $-140{ }^{\circ} \mathrm{C}$, the formation of an unstable crack front requires high energy. 
At this temperature, the unstable crack propagation occurs in a quasi-cleavage manner, while the dimples can only be found on a few tear ridges.

\subsubsection{Three-point Bending Tests}

The fracture surfaces of the V-notch Charpy specimen after bending tests with the low strain rate are quite different from those after tensile tests (Figure 7). The fracture surface of the specimen tested at room temperature consists of a general sequence of all characteristic fracture zones, i.e., the zone of fracture initiation followed by the fibrous zone of stable crack propagation, then the zone of unstable crack propagation, and the final shear-lip zone of arrested crack propagation (Figure 7a). The zone of unstable crack propagation covers the largest area of the fracture surface irrespective of test temperature. Decreasing temperature expands this unstable zone and reduces the other zones until their complete disappearance. The shear-lip zone almost disappears at $T<0{ }^{\circ} \mathrm{C}$ (Figure $7 \mathrm{c}, \mathrm{d}$ ). This correlates with an absence of the arrest of crack propagation on the load-deflection curves in Figure 4.

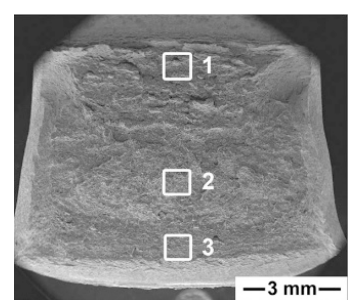

(a)

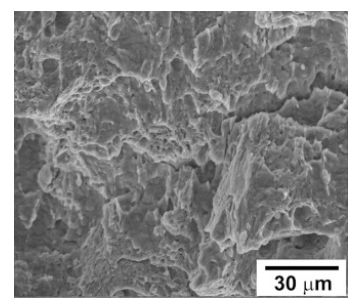

(a1)

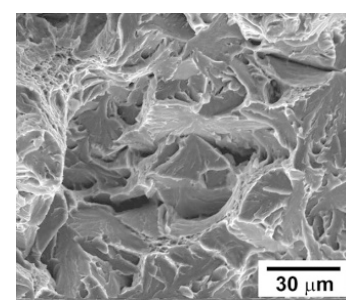

(a2)

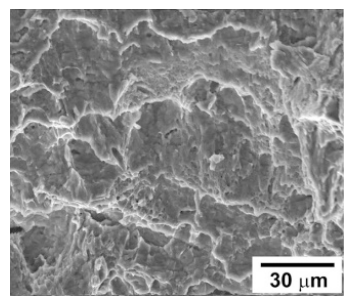

(a3)

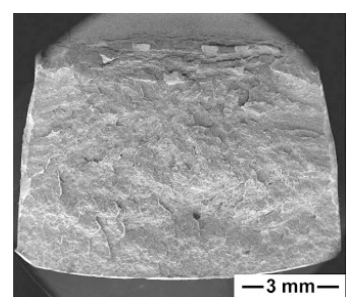

(b)

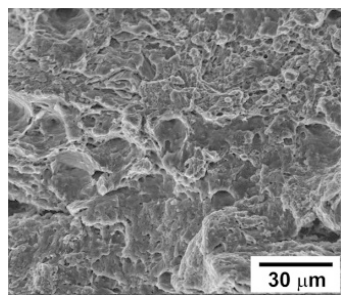

(b1)

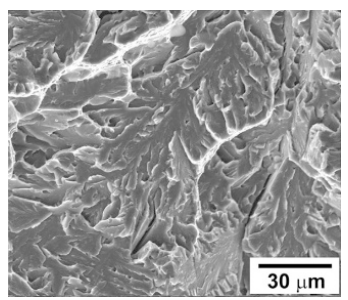

(b2)

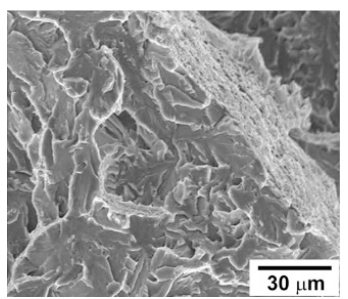

(b3)

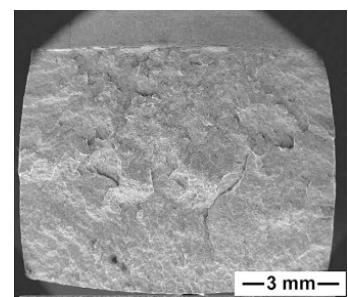

(c)

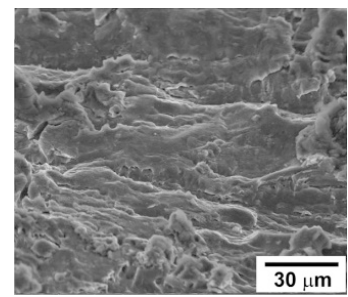

(c1)

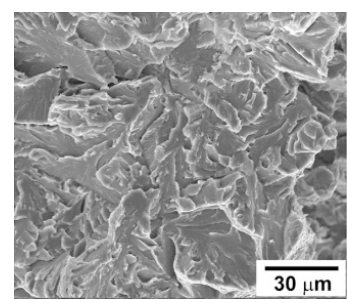

(c2)

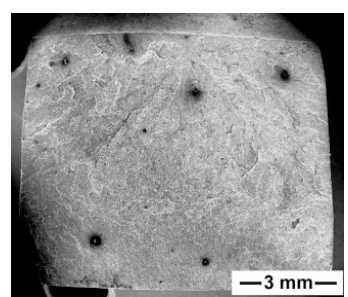

(d)

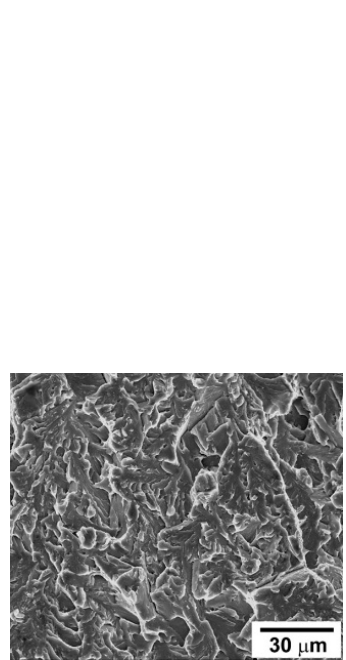

(d2)

Figure 7. Macrographs of the fracture surface in the Charpy V-notch specimen after three-point bending test at $20^{\circ} \mathrm{C}(\mathbf{a}),-40{ }^{\circ} \mathrm{C}(\mathbf{b}),-80{ }^{\circ} \mathrm{C}$ (c)and $-140{ }^{\circ} \mathrm{C}(\mathbf{d})$ along with the SEM images of the crack initiation/stable crack propagation zone (portion 1), the unstable crack propagation zone (center portion 2) and the shear-lip zone (portion 3) in low to high magnifications. 
At ambient temperature, the stable crack propagation in the initiation and fibrous zones occurs through the ductile mechanism. The transition to unstable crack propagation is attributed to the transition from dimple fracture to quasi-cleavage fracture mode in the fibrous zone. In addition, the intergranular fracture along the grain boundaries is observed in the unstable crack propagation zone (Figure 7a). The voids can nucleate on the boundaries of prior austenite grains. However, the propagation of crack fronts along these boundaries occurs in a few grains. The transgranular cracking is dominant. Cleavage fracture is arrested in the shear-lip zone, where the coarse and fine shallow dimples suggest ductile fracture. At $-40{ }^{\circ} \mathrm{C}$, the fine dimples are dominant in the initiation and fibrous zones (Figure $7 \mathrm{~b}$ ). The quasi-cleavage fracture occurs in the shear-lip zone, where very fine dimples are observed on the extended tear ridges. The area of stable crack propagation reduces with decreasing the temperature (Table 2). The unstable crack propagation occurs after the formation of a subcritical crack front in the initiation zone. Therefore, the previously created flaw significantly modifies the fracture mechanisms. At $T>T_{28 \mathrm{~J}}$, the unstable cleavage fracture occurs after the stages of subcritical crack initiation and stable crack propagation. In contrast, V-notch provides higher local stresses than required for unstable cleavage fracture at $T<T_{28 \mathrm{~J}}$. Under such conditions, V-notch plays a role of a crack susceptible to unstable propagation.

Table 2. The zone sizes ( $\mathrm{mm}$ ) as measured on SEM images crosswise to the notch.

\begin{tabular}{cccccc}
\hline \multirow{2}{*}{ Zone } & \multicolumn{5}{c}{ Test Temperature, ${ }^{\circ} \mathbf{C}$} \\
\cline { 2 - 6 } & $\mathbf{8 0}$ & $\mathbf{2 0}$ & $\mathbf{- 4 0}$ & $\mathbf{- 8 0}$ & $\mathbf{- 1 4 0}$ \\
\hline Initiation and fibrous zones & 4.3 & 2.8 & 1.5 & 0.2 & 0.1 \\
Unstable crack zone & - & 2.9 & 5.5 & 7.7 & 7.9 \\
Shear-lip zone & 3.5 & 3.3 & 0.7 & 0.1 & - \\
Total & 7.8 & 7.9 & 7.7 & 8.0 & 8.0 \\
\hline
\end{tabular}

\section{Discussion}

High-chromium steels are a unique material that exhibits a concurrent increase in strength and ductility with decreasing temperature [7]. Uniform elongation increases with a decrease in tensile temperature that is usually related to the increased stability of plastic flow $[7,24,28,29]$. This presumption is supported by the analysis of the strain-hardening, $d \sigma / d \varepsilon$, calculated as the first derivative of the true stress from the true strain (Figure 8). The strain-hardening during tensile tests can be subdivided into three stages. Those are the first stage of a rapid decrease in $d \sigma / d \varepsilon$ at early deformation, the second stage of parabolic strain dependence of $d \sigma / d \varepsilon$ and the third stage of accelerated decrease in $d \sigma / d \varepsilon$. It is clearly seen in Figure 9 that the magnitude of $d \sigma / d \varepsilon$ increases as temperature decreases. The value of $d \sigma / d \varepsilon$ corresponding to the second stage onset increases from 2000 to $2800 \mathrm{MPa}$ with a decrease in temperature from $20^{\circ} \mathrm{C}$ to $-140^{\circ} \mathrm{C}$. This enhances both uniform elongation and total elongation-to-failure. It is worth noting that P92-type steels exhibit the same work hardening behavior at cryogenic temperatures despite the dominance of quasi-cleavage fracture in the tensioned specimens [7]. The unique temperature effect on the strength and ductility in high-chromium steels is similar to that for fccalloys $[7,28]$. Therefore, these steels are highly tough in tension down to liquid nitrogen temperature in the absence of a notch, because a high energy is necessary for the formation of critical macrocracks susceptible for unstable propagation.

Let us consider the notch effect on the fracture behavior in more detail. The maximal tensile stress in the minimum cross section of the specimen at the notch root can be evaluated as follows [25]:

$$
\sigma=\frac{\beta L P}{2 C_{f}(W-a)^{2} B}
$$

where $L$ is the span $(40 \mathrm{~mm}) ; P$ is the load; $W$ is the specimen width $(10 \mathrm{~mm}) ; B$ is the specimen thickness $(10 \mathrm{~mm}) ; a$ is the notch depth $(2 \mathrm{~mm}) ; C_{\mathrm{f}}$ is the constraint factor (the ratio of the yield load to 
the load required to yield an unnotched specimen) that depends on the instrument tip $\left(C_{\mathrm{f}}=1.363\right.$ for ASTM tip [7,25]); and $\beta$ is a constant depending on the yielding criterion (it is equal to 2 for the Tresca criterion $[7,25])$.

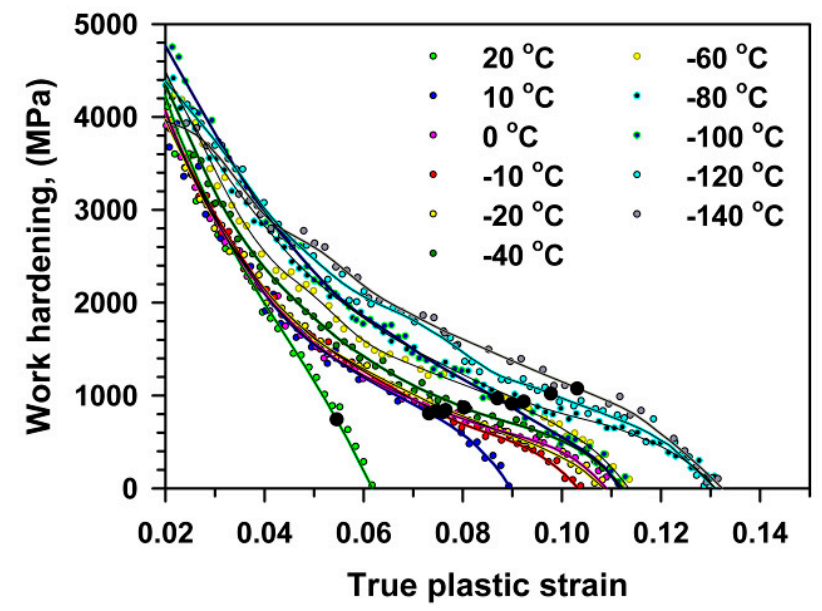

Figure 8. Strain-hardening during tensile tests at different temperatures.

The maximum stress and the brittle fracture stress for impact and three-point bending tests, $\sigma_{\mathrm{m}} \mathrm{I}$, $\sigma_{\mathrm{F}}{ }^{\mathrm{I}}, \sigma_{\mathrm{m}}{ }^{\mathrm{B}}, \sigma_{\mathrm{F}}{ }^{\mathrm{B}}$, respectively, calculated by Equation (1) using the values of maximal $\left(\mathrm{P}_{\mathrm{m}}\right)$ and fracture $\left(\mathrm{P}_{\mathrm{F}}\right)$ loads (Figures 3 and 4 ), are presented in Figure 9 along with $\sigma_{0.2}$ and $\sigma_{\mathrm{m}}^{\mathrm{T}}$ obtained from tensile tests (Figure 2, Table 1). An inspection of Figure 9 with the temperature dependence of the V-notch Charpy-absorbed energy during impact and the three-point bending tests (Figure 10) suggests that the already created flaw plays a key role in the DBT of the high-chromium steel. Charpy V-notched tests under the static and dynamic loading show evidences for rather large plastic deformation providing significant absorbed energy at $T \geq T_{28 \mathrm{~J}}[23,25,30]$. At $T<T_{28 \mathrm{~J}}$, the steel becomes brittle, and the already created flaw initiates an unstable crack propagation with a quite small zone of plastic deformation ahead of the flaw $[7,23]$. In the upper shelf region, the dynamic loading provides an almost $75 \%$ increase in the Charpy V-notch absorbed energy compared with the static loading (Figure 10). This is associated with higher stresses for crack initiation and the larger stage of stable crack propagation during impact tests than during three-point bending tests (Figures 3 and 4).

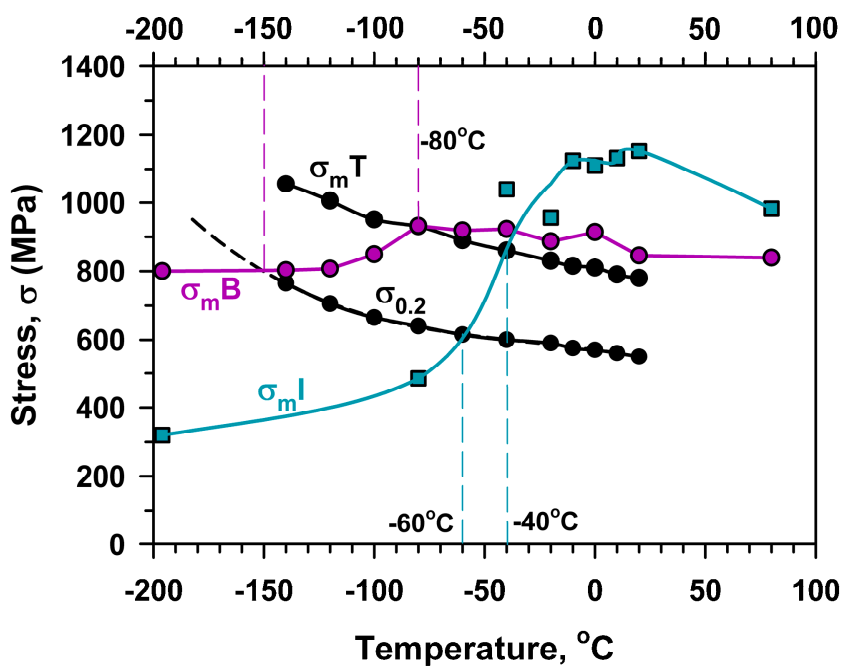

Figure 9. Temperature dependence of the maximum stresses during impact $\left(\sigma_{m}{ }^{I}\right)$ and three-point bending $\left(\sigma_{m}{ }^{B}\right)$ tests calculated by Equation (1) along with the yield strength $\left(\sigma_{0.2}\right)$ and the maximal stresses $\left(\sigma_{\mathrm{m}}^{\mathrm{T}}\right)$ during tensile tests. 


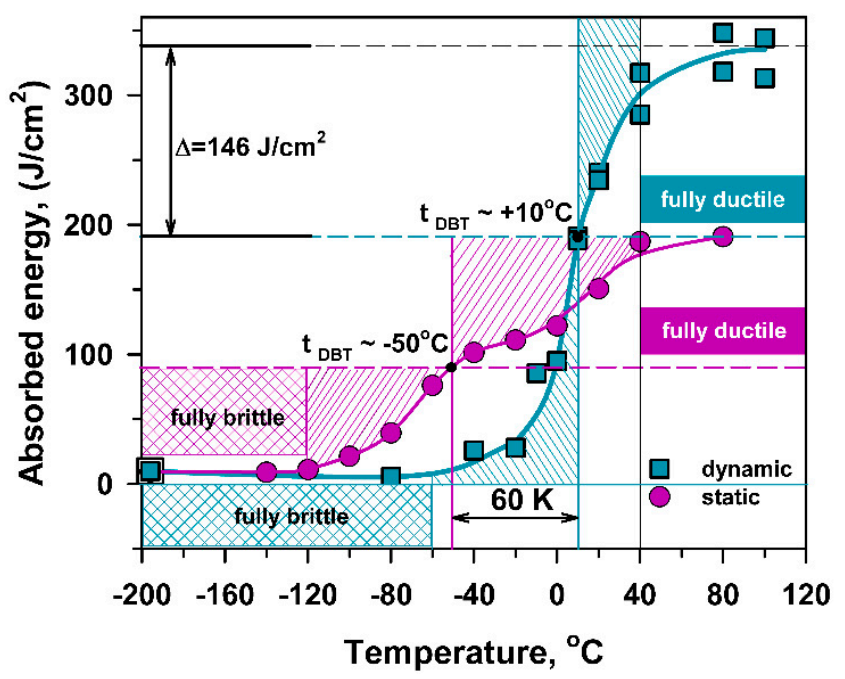

Figure 10. Effect of temperature on the V-notch Charpy absorbed energy for impact [21] and three-point bending tests corresponding to dynamic and static loading.

According to the Yoffee diagram [31-34], the brittle fracture should occur at temperatures below an intersection of the $\sigma_{0.2}$ and $\sigma_{\mathrm{m}}$ curves for different types of loading, i.e., $\sigma_{\mathrm{m}}{ }^{\mathrm{I}}$ and $\sigma_{\mathrm{m}}{ }^{\mathrm{B}}$ for impact and three-point bending tests, respectively (Figure 9). Under dynamic loading, the temperature of the $\sigma_{0.2}$ and $\sigma_{\mathrm{m}}{ }^{\mathrm{I}}$ intersection is higher than that for the static loading (three-point bending tests). These characteristic temperatures of $-150^{\circ} \mathrm{C}$ and $-60^{\circ} \mathrm{C}$ for the static and dynamic loading, respectively, can be considered as the temperatures of embrittlement. This is also confirmed by the fully brittle fracture and the low absorbed energy in the temperature range corresponding to $\sigma_{0.2} \geq \sigma_{\mathrm{m}}$.

The effect of a stress concentrator on the fracture behavior can be clarified by a comparison of $\sigma_{\mathrm{m}}^{\mathrm{T}}$ with $\sigma_{\mathrm{m}}^{\mathrm{I}}$ and $\sigma_{\mathrm{m}}^{\mathrm{B}}$ in Figure 9. The maximal true stresses correspond to the onset of necking during tensile tests, and the maximal impact/bending stress is indicative for the crack formation and propagation during V-notch tests $[7,21]$. The stresses required for the neck formation $\left(\sigma_{\mathrm{m}}{ }^{\mathrm{T}}\right)$ during the tensile tests and those for the crack initiation $\left(\sigma_{\mathrm{m}} \mathrm{B}\right)$ during the three-point bending tests are the same in the range of $T \geq-80^{\circ} \mathrm{C}$ because of almost the same strain rates in these two types of loading. Therefore, the presence of V-notch does not affect the fracture at $T \geq-80^{\circ} \mathrm{C}$, whereas at lower temperatures the stresses required to fracture initiation for the notched specimens are much lower than the maximal true stresses during tensile tests. On the other hand, the maximal impact stress attains $\sigma_{\mathrm{m}}{ }^{\mathrm{T}}$ at $T=-40{ }^{\circ} \mathrm{C}$. The values of $\sigma_{\mathrm{m}}{ }^{\mathrm{I}}$ exceed $\sigma_{\mathrm{m}}{ }^{\mathrm{T}}$ at $T>-40^{\circ} \mathrm{C}$. This is attributed to the significant absorbed energy at the stage of crack initiation. At $T<-40{ }^{\circ} \mathrm{C}, \sigma_{\mathrm{m}}{ }^{\mathrm{I}}$ is lower than $\sigma_{\mathrm{m}}{ }^{\mathrm{T}}$ because the energy for crack nucleation during impact loading of V-notched specimens rapidly decreases with temperature. Thus, the ability of the steel to resist the formation of a crack with critical dimensions is a key factor to prevent fracture upon dynamic loading. It is obvious that $T_{28 \mathrm{~J}}=-27^{\circ} \mathrm{C}$ adequately describes DBT under dynamic loading. At this temperature, the true stress for the onset of necking during tension and the stress for crack initiation are nearly the same (Figure 9 ). Therefore, $T_{28 \mathrm{~J}}$ determined by the impact test could be considered as a critical temperature describing DBT for the ductile high-Cr steels, instead of DBTT measured as that corresponding to the half between the upper shelf and lower shelf energies.

The high work-hardening rate during tensile tests provides the high stored energy before necking. In addition, the formation of a crack with a critical size results from the propagation of microcracks in a ductile manner. Hence, a high energy is necessary to initiate the unstable crack propagation [7], and the steel is tough even at cryogenic temperatures. An embrittlement is a phenomenon of the notched specimens of this steel; it appears at temperatures when the size of the previously created flaw becomes higher than the size of the critical crack susceptible to unstable propagation. If the size of the previously created flaw is lower than the dimension of the critical crack, the stable crack 
propagation takes place and the steel is tough. The toughness of the steel is controlled by the area of stable crack propagation.

\section{Conclusions}

The fracture behavior of a $10 \% \mathrm{Cr}$ steel with $0.003 \% \mathrm{~N}$ and $0.008 \% \mathrm{~B}$ was studied in the tensile tests and three-point bending tests of Charpy V-notch specimens. The main results can be summarized as follows.

1. Total elongation and ultimate tensile strength increased from $18 \%$ to $24 \%$ and from $710 \mathrm{MPa}$ to $925 \mathrm{MPa}$, respectively, with a decrease in temperature from $20^{\circ} \mathrm{C}$ to $-140^{\circ} \mathrm{C}$ due to an expansion of the strain hardening stage. The formation of crack with critical dimension occurred upon necking accompanied by microcrack nucleation and growth in a ductile manner absorbing high energy. The unstable crack propagation in a brittle manner was observed at $-140{ }^{\circ} \mathrm{C}$ only.

2. A temperature of $-50^{\circ} \mathrm{C}$ corresponded to the half of the sum of the upper shelf energy and the lower shelf energy, and was considered as a temperature of ductile-brittle transition for three-point bending tests of V-notched specimens. This temperature was lower than the fracture appearance transition temperature by about $30^{\circ} \mathrm{C}$. A rather low $28 \mathrm{~J}$ transition temperature, $T_{28 \mathrm{~J}}$ $=-90^{\circ} \mathrm{C}$, was attributed to short-range crack propagation in stable manner. The maximal stress during three-point bending and the maximal true stress during tensile tests were almost the same at temperatures above $-80^{\circ} \mathrm{C}$. In contrast, the stresses required to fracture initiation for the notched specimens were much lower than the maximal true stresses during tensile tests at $T<-80^{\circ} \mathrm{C}$. Therefore, the presence of V-notch scarcely affects the fracture at $T \geq-80^{\circ} \mathrm{C}$, whereas the steel becomes highly susceptible to flaw lower temperatures.

Author Contributions: Conceptualization, R.K.; methodology, R.M. and N.D.; formal analysis, A.B.; investigation, R.M.; writing —original draft preparation, R.M. and N.D.; writing-review and editing, A.B.; supervision, N.D.; project administration, N.D.; funding acquisition, R.K. All authors have read and agreed to the published version of the manuscript.

Funding: The study was supported by the Ministry of Education and Science of Russian Federation, under project of Government Task No. 11.2868.2017/PCh (11.2868.2017/4.6).

Acknowledgments: The authors are grateful to the personnel of the Joint Research Center, [Technology and Materials], Belgorod State University, for their assistance with instrumental analysis.

Conflicts of Interest: The authors declare no conflict of interest.

\section{References}

1. Abe, F.; Kern, U.T.; Vismanathan, R. Creep-Resistanat Steels; Woodhead Publishing: Cambridge, UK, 2008; ISBN 978-1-84265-129-2.

2. Kaybyshev, R.O.; Skorobogatykh, V.N.; Shchenkova, I.A. New martensitic steels for fossil power plant: Creep resistance. Phys. Met. Metallogr. 2010, 109, 186-200. [CrossRef]

3. Fedoseeva, A.; Dudova, N.; Kaibyshev, R. Role of Tungsten in the Tempered Martensite Embrittlement of a Modified 9 Pct Cr Steel. Metall. Mater. Trans. A 2017, 48, 982-998. [CrossRef]

4. Dudova, N.; Mishnev, R.; Kaibyshev, R. Effect of tempering on microstructure and mechanical properties of boron containing 10\% Cr steel. ISIJ Int. 2011, 51, 1912-1918. [CrossRef]

5. Kipelova, A.Y.; Belyakov, A.N.; Skorobogatykh, V.N.; Shchenkova, I.A.; Kaibyshev, R.O. Tempering-induced structural changes in steel 10Kh9K3V1M1FBR and their effect on the mechanical properties. Met. Sci. Heat Treat. 2010, 52, 100-110. [CrossRef]

6. Kitahara, H.; Ueji, R.; Tsuji, N.; Minamino, Y. Crystallographic features of lath martensite in low-carbon steel. Acta Mater. 2006, 54, 1279-1288. [CrossRef]

7. Dudko, V.; Fedoseeva, A.; Kaibyshev, R. Ductile-brittle transition in a 9\% Cr heat-resistant steel. Mater. Sci. Eng. A 2017, 682, 73-84. [CrossRef] 
8. Chatterjee, A.; Chakrabarti, D.; Moitra, A.; Mitra, R.; Bhaduri, A.K. Effect of normalization temperatures on ductile-brittle transition temperature of a modified 9Cr-1Mo steel. Mater. Sci. Eng. A 2014, 618, 219-231. [CrossRef]

9. Wakai, E.; Okubo, N.; Ando, M.; Yamamoto, T.; Takada, F. Reduction method of DBTT shift due to irradiation for reduced-activation ferritic/martensitic steels. J. Nucl. Mater. 2010, 398, 64-67. [CrossRef]

10. Chatterjee, A.; Chakrabarti, D.; Moitra, A.; Mitra, R.; Bhaduri, A.K. Effect of deformation temperature on the ductile-brittle transition behavior of a modified 9Cr-1Mo steel. Mater. Sci. Eng. A 2015, 630, 58-70. [CrossRef]

11. Chatterjee, A.; Moitra, A.; Bhaduri, A.K.; Mitra, R.; Chakrabarti, D. Dynamic fracture behaviour of thermo-mechanically processed modified 9Cr-1Mo steel. Eng. Fract. Mech. 2015, 149, 74-88. [CrossRef]

12. Sathyanarayanan, S.; Basu, J.; Moitra, A.; Sasikala, G.; Singh, V. Effect of Thermal Aging on Ductile-Brittle Transition Temperature of Modified 9Cr-1Mo Steel Evaluated with Reference Temperature Approach Under Dynamic Loading Condition. Metall. Mater. Trans. A 2013, 44, 2141-2155. [CrossRef]

13. Hu, X.; Huang, L.; Yan, W.; Wang, W.; Sha, W.; Shan, Y.; Yang, K. Evolution of microstructure and changes of mechanical properties of CLAM steel after long-term aging. Mater. Sci. Eng. A 2013, 586, 253-258. [CrossRef]

14. Zhong, W.; Wang, W.; Yang, X.; Li, W.; Yan, W.; Sha, W.; Wang, W.; Shan, Y.; Yang, K. Relationship between Laves phase and the impact brittleness of P92 steel reevaluated. Mater. Sci. Eng. A 2015, 639, 252-258. [CrossRef]

15. Semba, H.; Abe, F. Alloy design and creep strength of advanced $9 \%$ Cr USC boiler steels containing high concentration of boron. Energy Mater. 2006, 1, 238-244. [CrossRef]

16. Tabuchi, M.; Hongo, H.; Abe, F. Creep Strength of Dissimilar Welded Joints Using High B-9Cr Steel for Advanced USC Boiler. Metall. Mater. Trans. A 2014, 45, 5068-5075. [CrossRef]

17. Liu, Y.; Tsukamoto, S.; Sawada, K.; Tabuchi, M.; Abe, F. Precipitation Behavior in the Heat-Affected Zone of Boron-Added 9Cr-3W-3Co Steel during Post-Weld Heat Treatment and Creep Deformation. Metall. Mater. Trans. A 2015, 46, 1843-1854. [CrossRef]

18. Mishnev, R.; Dudova, N.; Fedoseeva, A.; Kaibyshev, R. Microstructural aspects of superior creep resistance of a 10\% Cr martensitic steel. Mater. Sci. Eng. A 2016, 678, 178-189. [CrossRef]

19. Sahara, R.; Matsunaga, T.; Hongo, H.; Tabuchi, M. Theoretical Investigation of Stabilizing Mechanism by Boron in Body-Centered Cubic Iron Through (Fe,Cr)23(C,B)6 Precipitates. Metall. Mater. Trans. A 2016, 47, 2487-2497. [CrossRef]

20. Dudova, N.; Kaibyshev, R. On the Precipitation Sequence in a 10\% Cr Steel under Tempering. ISIJ Int. 2011, 51, 826-831. [CrossRef]

21. Mishnev, R.; Dudova, N.; Dudko, V.; Kaibyshev, R. Impact toughness of a $10 \%$ Cr steel with high boron and low nitrogen contents. Mater. Sci. Eng. A 2018, 730, 1-9. [CrossRef]

22. Jurči, P.; Dománková, M.; Hudáková, M.; Ptačinová, J.; Pašák, M.; Palček, P. Characterization of microstructure and tempering response of conventionally quenched, short- and long-time sub-zero treated PM Vanadis 6 ledeburitic tool steel. Mater. Charact. 2011, 134, 398-415. [CrossRef]

23. Krauss, G. Steels: Processing, Structure, and Performance; ASM International: Materials Park, OH, USA, 2005.

24. Antolovich, S.D.; Armstrong, R.W. Plastic strain localization in metals: Origins and consequences. Prog. Mater. Sci. 2014, 59, 1-160. [CrossRef]

25. Chaouadi, R.; Fabry, A. On the utilization of the instrumented Charpy impact test for characterizing the flow and fracture behavior of reactor pressure vessel steels. In From Charpy to Present Impact Testing; Francois, D., Pineau, A., Eds.; Elsevier Science Ltd. and ESIS: Oxford, UK, 2002.

26. Kerlins, V. Modes of Fracture. In ASM Handbook, Fractography; Mills, K., Davis, J.R., Destefani, J.D., Dieterich, D., Eds.; ASM International: Materials Park, OH, USA, 1987; Volume 12.

27. Knott, J.F.; Met, B. Fundamentals of Fracture Mechanics; Butterworths: London, UK, 1973.

28. Vinogradov, A.; Yasnikov, I.S.; Matsuyama, H.; Uchida, M.; Kaneko, Y.; Estrin, Y. Controlling strength and ductility: Dislocation-based model of necking instability and its verification for ultrafine grain 316L steel. Acta Mater. 2016, 106, 295-303. [CrossRef]

29. Jobba, M.; Mishra, R.K.; Niewczas, M. Flow stress and work-hardening behaviour of Al-Mg binary alloys. Int. J. Plast. 2015, 65, 43-60. [CrossRef]

30. ASTM E23-05. Standard test methods for notched bar impact testing of metallic materials. In Annual Book of ASTM Standards, 03.01; ASTM International: West Conshohocken, PA, USA, 2005. 
31. Morris, J.W., Jr. MATERIALS SCIENCE: Stronger, Tougher Steels. Science 2008, 320, 1022-1023. [CrossRef]

32. Morris, J.W., Jr. On the Ductile-Brittle Transition in Lath Martensitic Steel. ISIJ Int. 2011, 51, 1569-1575. [CrossRef]

33. Kimura, Y.; Inoue, T. Influence of Warm Tempforming on Microstructure and Mechanical Properties in an Ultrahigh-Strength Medium-Carbon Low-Alloy Steel. Metall. Mater. Trans. A 2013, 44, 560-576. [CrossRef]

34. Kimura, Y.; Inoue, T. Influence of Carbon Content on Toughening in Ultrafine Elongated Grain Structure Steels. ISIJ Int. 2015, 55, 1135-1144. [CrossRef]

(C) 2019 by the authors. Licensee MDPI, Basel, Switzerland. This article is an open access article distributed under the terms and conditions of the Creative Commons Attribution (CC BY) license (http://creativecommons.org/licenses/by/4.0/). 